\title{
Editorial to the head and neck cancer-series
}

The term 'head and neck cancer' represents a diverse group of aggressive neoplasms that affects nearly a half a million individuals worldwide. These cancers can arise in several sites within the upper aerodigestive tract including the oral cavity, pharynx, larynx, thyroid and salivary glands and therefore exhibit considerable heterogeneity in biology and clinical behavior.

Indeed, development of novel radiation delivery methods and recent approval of immune checkpoint inhibitors have led to improved outcomes in this patient population. However, disease recurrence remains a clinical challenge. Furthermore, a majority of patients with head and neck cancers experience prolonged treatment induced morbidities including weight loss severe dry mouth (xerostomia), mucositis, dysphagia and loss of dentition due to aggressive chemoradiation regimens and/ or surgical intervention. The articles published in this current series review our current knowledge on the biology of these neoplasms and clinical challenges encountered in the management of these patients.

In the first paper, Rivers et al. focus on the role of intravenous fluids in managing pain secondary to oral mucositis in head and neck cancer patients. Two subsequent original research articles by Han et al. provide the results of matched pair analyses on survival outcomes in head and neck cancer patients with alternative regimens compared to standard concurrent chemoradiation and on the prognostic relevance of weight loss during radiation therapy in head and neck cancer. Dr. Farah reviews our current understanding on the molecular landscape of head and neck cancers and the therapeutic implications of our insights into the basic biology of these cancers. And finally, Singh and colleagues provide a narrative review of the management of oral mucositis in head and neck cancer patients.

As the guest editor of this series, I am confident that these original research articles and reviews will not only be of interest and value to clinicians and scientists in head and neck oncology but also to the broad readership of Annals of Translational Medicine.

\section{Acknowledgments}

Funding: This work was supported by Roswell Park's Cancer Center Support Grant from the National Cancer Institute P30CA016056 and grants, R01DE024595, R01CA204636, R01CA243456.

\section{Footnote}

Provenance and Peer Review: This article was commissioned by the editorial office, Annals of Translational Medicine for the series "Head and Neck Cancers-Disease Biology, Diagnostics, Prevention and Management". The article did not undergo external peer review.

Conflicts of Interest: The author has completed the ICMJE uniform disclosure form (available at http://dx.doi.org/10.21037/ atm-21-1224). The series "Head and Neck Cancers-Disease Biology, Diagnostics, Prevention and Management" was commissioned by the editorial office without any funding or sponsorship. MS served as the unpaid Guest Editor of the series and serves as an unpaid editorial board member of Annals of Translational Medicine from Aug 2019 to Jul 2021. The author has no other conflicts of interest to declare.

Ethical Statement: The author is accountable for all aspects of the work in ensuring that questions related to the accuracy or integrity of the work are appropriately investigated and resolved.

Open Access Statement: This is an Open Access article distributed in accordance with the Creative Commons AttributionNonCommercial-NoDerivs 4.0 International License (CC BY-NC-ND 4.0), which permits the non-commercial replication and distribution of the article with the strict proviso that no changes or edits are made and the original work is properly cited (including links to both the formal publication through the relevant DOI and the license). See: https://creativecommons.org/licenses/by-nc$\mathrm{nd} / 4.0 /$. 


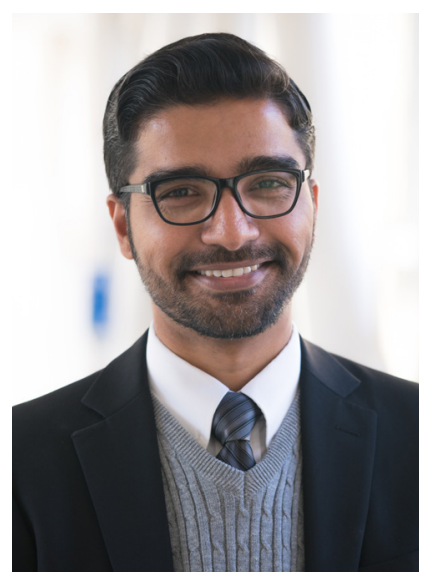

Mukund Seshadri

Mukund Seshadri, PhD, DDS

Professor of Oncology and Chair, Department of Oral Oncology, Roswell Park Comprehensive Cancer Center, Buffalo, NY, USA.

(Email: Mukund.Seshadri@roswellpark.org)

Submitted Mar 15, 2021. Accepted for publication Mar 19, 2021. doi: $10.21037 / \mathrm{atm}-21-1224$

View this article at: http://dx.doi.org/10.21037/atm-21-1224

Cite this article as: Seshadri M. Editorial to the head and neck cancer-series. Ann Transl Med 2021;9(10):911. doi: 10.21037/ atm-21-1224 